\title{
Autosomal Dominant Lateral Temporal Lobe Epilepsy
}

National Cancer Institute

\section{Source}

National Cancer Institute. Autosomal Dominant Lateral Temporal Lobe Epilepsy. NCI

Thesaurus. Code C141441.

An autosomal dominant condition caused by mutation(s) in the LGI1 gene, encoding leucine-rich g lioma-inactivated protein 1. It is characterized by partial seizures originating in the temporal lobe and often accompanied by auditory sensory manifestations. 